\title{
Relaciones literarias entre Portugal y España en los años 40: la cultura oficial y la recepción de Fernando Pessoa
}

\section{Antonio Sáez Delgado}

To cite this article: Antonio Sáez Delgado (2018): Relaciones literarias entre Portugal y España en los años 40: la cultura oficial y la recepción de Fernando Pessoa, Journal of Iberian and Latin American Research, DOI: 10.1080/13260219.2018.1471154

To link to this article: https://doi.org/10.1080/13260219.2018.1471154

Published online: 06 Jun 2018.

Submit your article to this journal $\square$

Џ Article views: 1

Q View related articles ¿

View Crossmark data ¿ 


\title{
Relaciones literarias entre Portugal y España en los años 40: la cultura oficial y la recepción de Fernando Pessoa
}

\author{
Antonio Sáez Delgado \\ Universidade de Évora / Centro de Estudos Comparatistas da Universidade de Lisboa
}

\begin{abstract}
The presence of Fernando Pessoa in Spain in the 1940s, after the Civil War, provides an interesting research area to understand the relations between the Portuguese and Spanish literatures of that time. In a moment marked by the new social and political reality of the postwar period, with a pervasive official and officialist culture, the reception of the author of the heteronyms by writers and intellectuals such as José García Nieto, Gerardo Diego or Joaquín de Entrambasaguasthrough the relationship developed between Eugenio Montes and António Ferro-defines a landmark in the literary and cultural relations between the two major Iberian literatures, which should now be revisited in the light of new elements of analysis.
\end{abstract}

\section{RESUMEN}

La presencia de Fernando Pessoa en España en los años 40, tras la Guerra Civil, ofrece un interesante campo de trabajo para comprender las relaciones entre las literaturas portuguesa y española de aquel momento. En un tiempo marcado por la nueva realidad social y política de la postguerra, con una cultura oficial y oficialista omnipresente, la recepción del autor de los heterónimos por parte de escritores e intelectuales como José García Nieto, Gerardo Diego o Joaquín de Entrambasaguas-a través del eje de contactos establecido entre Eugenio Montes y António Ferro-define una baliza fundamental en las relaciones literarias y culturales entre las dos mayores literaturas ibéricas, que ahora conviene revisitar a la luz de nuevos elementos de análisis.

\section{KEYWORDS}

Fernando Pessoa; Iberian Studies; Spanish literature; Portuguese literature

\section{PALABRAS CLAVE}

Fernando Pessoa; estudios ibéricos; literatura española; literatura portuguesa

El estudio de las relaciones culturales y literarias entre Portugal y España a lo largo del siglo XX dibuja un escenario que propicia, cada vez más, la posibilidad de cuestionar el tópico de los dos países que viven de espaldas, facilitando el acercamiento a una nueva visión en la que, si se rasca la piel de la realidad histórica, es posible encontrar numerosos autores, movimientos y corrientes que atravesaron la frontera de los dos estados ibéricos. En ese contexto, la presencia de la obra de Fernando Pessoa en España ha ido pasando, poco a poco, de ser un terreno baldío, casi inexplorado, a constituirse en un territorio con balizas cada vez más iluminadas y firmes. La huella del creador de los heterónimos, desde la primera traducción realizada por Rogelio Buendía en $1923^{1}$ hasta la actualidad, ha dejado y sigue 
dejando rastros notables, tanto desde el punto de vista de sus permanentes traducciones como desde el de la producción académica, como puso de manifiesto la exposición Fernando Pessoa en España, amparada por las Bibliotecas Nacionales de los dos países. ${ }^{2}$

Estudios críticos sobre la presencia de Pessoa en España como los realizados por Nicolás Extremera y Luisa Trías, ${ }^{3}$ César Antonio Molina, ${ }^{4}$ Pilar Vázquez Cuesta, ${ }^{5}$ Ángel Crespo ${ }^{6}$ o, más recientemente, José Francisco Ruiz Casanova ${ }^{7}$ o Antonio Sáez Delgado ${ }^{8}$ han aportado numerosos datos que facilitan la reconstrucción del papel desempeñado por el autor de Mensagem en el contexto de las relaciones literarias entre ambos países, centrándose de manera especial en su tiempo de vida (1888-1935). Sin embargo, el periodo que sigue a su muerte, muy en especial los años 40 , aún no ha sido suficientemente estudiado, a pesar de la importancia que encarna, al ser el momento en el que comienza a edificarse la figura del escritor en el contexto nacional e internacional.

Tanto los ensayos de los autores mencionados como algún otro dedicado a las relaciones literarias entre ambos países durante las dictaduras de Salazar y Franco, como el de Eduardo Alonso Romo, ${ }^{9}$ capitalizan la huella de Pessoa en España en los años 40 en sus principales cotas: la aparición de la primera colectánea de poemas pessoanos (Fernando Pessoa, Poesías, 1946, con introducción y selección de Joaquín de Entrambasaguas) ${ }^{10}$ y la edición del primer ensayo de magnitud dedicado a la obra del autor de los heterónimos (obra de IldefonsoManuel Gil y recogido en su libro Ensayos sobre poesía portuguesa, 1948). ${ }^{11}$ Sin embargo, como presagia el lúcido análisis realizado por Jordi Cerdà ${ }^{12}$ en el artículo más importante dedicado a nuestro asunto, la posguerra española se constituye en un interesantísimo campo de trabajo para evaluar, desde un punto de vista que entrevere elementos estéticos e ideológicos, el contexto en el que surgen esas primeras muestras poética y ensayística, en medio de circunstancias que ahora nos interesa traer a la superficie.

Es evidente que la Guerra de 1936 supone un auténtico terremoto en el amplio y plural proceso de modernización que vivían las artes españolas, afectando de manera directa al singular momento de esplendor que vivía su literatura. Con el final de la Guerra y la imposición de la dictadura comienza un proceso de construcción del aparato fascista (o, tal vez con más rigor, nacional-católico) del Estado español que concede, interesadamente, un papel importante a la cultura, con el objetivo fundamental de legitimar un área básica en el pensamiento oficial profundamente dañada por el exilio masivo de los intelectuales y escritores republicanos, que crean una nueva España, esta vez en la diáspora, con voces de gran prestigio internacional. El aparato de la política cultural y de propaganda franquista intentó, sin ahorrar esfuerzos, camuflar que, como afirma Jordi Gracia, "el déficit de cabezas de algún peso es de pura bancarrota frente al bando leal a la República, y después exiliado," ${ }^{13}$ sirviéndose para ello de un amplio despliegue de cargos, instituciones, editoriales y publicaciones oficialistas que dominaron el ecosistema literario de posguerra. Es en este contexto de elaboración de un discurso que aspiraba a convertirse en sistema ideológico, y probablemente muy cerca de su mismo epicentro, donde podemos situar algunos de los elementos más importantes de la presencia pessoana en España en los años 40, con nuevos datos que nos ayudan a conocer el contexto y la magnitud de sus huellas.

\section{El contexto de la recepción de Pessoa en España en los años 40}

Si la aparición inaugural de Pessoa en España se produce al empezar los años veinte, en el contexto del ultraísmo y de la mano de los poetas Adriano del Valle y Rogelio Buendía 
(autor, en septiembre de 1923 y en el periódico onubense La Provincia, de su primera traducción al español), esta primera recepción se prolongará en el tiempo de la vanguardia histórica, gracias a la labor de José de Almada Negreiros durante su estancia en Madrid, ${ }^{14}$ a través de la publicación del poema "Pierrot bêbado" en el Almanaque de las artes y las letras para 1928 coordinado por Gabriel García Maroto, único volumen de época en el que encontramos las firmas de Pessoa y Federico García Lorca.

Sin embargo, la que podríamos denominar segunda recepción pessoana, la de los años 40, responde a un momento estético realmente diferente, con la cadena de la modernidad y la vanguardia española rota en mil pedazos (y esparcida a lo largo del mundo: en México, en Francia, en Argentina, en Puerto Rico... allá donde hubiera escritores españoles exiliados) y con una literatura nacional dentro del estado español en la que se debatían y medían las fuerzas de la poesía arraigada-esto es, la de afán más clasicista y tradicional promulgada por los vencedores de la guerra-y la desarraigada-más social y existencialista, contraria al proteccionismo del que la primera gozó por parte del poder político-ambas con sus propios órganos de expresión.

Desde la aparición de "Pierrot bêbado" en 1928, y contando con la mención que la canónica Enciclopedia Espasa hace en 1935 de Pessoa como "el maestro" de la generación de Presença (en sincronía perfecta con el Veintisiete español), el siguiente vestigio de un texto del autor de los heterónimos en España surge en mayo de 1944, cuando el joven poeta Rafael Morales traduce el poema "Cualquier música..." en la revista Garcilaso. ${ }^{15}$ Conviene aquí, para ofrecer un retrato fiel del contexto en el que surge esta segunda traducción, detenernos a reflexionar, siquiera brevemente, sobre los diferentes matices estéticos e ideológicos presentes en la poesía-y en sus revistas-española del momento, así como en el papel que desempeñan en su sistema los mediadores culturales con los que contó Pessoa en España.

Así, Morales, que inaugura en 1943 la colección Adonais con Poemas del toro-libro que, de acuerdo con Charles David Ley, ${ }^{16}$ le granjea mucha fama-será licenciado en literatura portuguesa por la Universidad de Coimbra y traductor de Adolfo Casais Monteiro, Eça de Queirós, Fernando Namora o Alberto de Serpa, además de uno de aquellos poetas que experimenta el tránsito entre la poesía arraigada de corte estrófico tradicional representada por Garcilaso-donde publica el poema de Pessoa-y la poesía de raíz existencialista y social de un libro como Los desterrados (1947). Esta evolución y ambivalencia estética, por otro lado, no es ajena a un buen grupo de autores del momento y se manifiesta a través de sus colaboraciones en revistas variadas desde el punto de vista ideológico y estético, pues es fácil comprobar que el tránsito de poetas que colaboraron en cabeceras bien diferentes era habitual, y matiza en buena medida la supuesta radicalidad de esas publicaciones, que no cavaron en términos reales trincheras profundas en sus páginas, abriendo con frecuencia las puertas a autores que aprovechaban la ocasión para aparecer en varias de ellas, aun con matices ideológicos diferentes.

El ejemplo de Rafael Morales, segundo traductor de Pessoa al español, es significativo: además de en Garcilaso, escribe sobre materia portuguesa en las páginas de la oficialista Escorial (publica un artículo titulado "Laranjeira y Unamuno") y en las de La estafeta literaria. ${ }^{17}$ Como la suya, en definitiva, no es tampoco imposible encontrar firmas que frecuentan estas revistas y que también aparecen en Espadaña (1944-1951), publicación vinculada a la poesía desarraigada y deliberadamente distante de las corrientes oficialista y neoclásica, demostrando que el mestizaje estético estuvo al orden del día tanto en los autores como en las revistas, puesto que las diferencias establecidas entre ellas obedecían más a criterios 
atmosféricos que al veto radical a poetas colaboradores de otras cabeceras, ya que, en definitiva, como afirman Jordi Gracia y Domingo Ródenas, "no fueron revistas unívocas más allá de declaraciones oficiales o radicalizadas." 18 Jaume Pont ha explicado este proceso sin tapujos, añadiendo la brillante imagen de la "cortina de humo de la lírica":

L'estratègia era molt simple. Es tractava de camuflar interessadament, mitjançant la cortina de fum de la lírica, les consignes bel-licistes i patrioticopolítiques del nou règim, donant així una aparença de normalitat cultural. Més enllà de les línies poètiques de les revistes, aquestes acaben intercanviant noms de poetes i poesia de registres molt diversos. Aquesta operació es feia en nom de la Poesia, amb majúscules, en nom de la necessitat de publicació i, en últim terme, en nom d'un consens pragmàtic entre poetes que atenuava la bel.ligerància de corrents i tendències. ${ }^{19}$

A pesar de que revistas como Escorial o Garcilaso_vinculadas de alguna manera, oficial o estéticamente, al estado nuevo español y al nuevo orden de cosas-contaron en medio de ese intento de legitimización de la "nueva cultura" imperante con secciones dedicadas a la poesía extranjera-lo cual nos sirve para, al menos, atenuar la afianzada idea de que la España de los años 40 estuvo aislada por completo del contexto internacional- ${ }^{20}$ lo cierto es que no volveremos a encontrar la firma de Pessoa en el contexto de estas cabeceras. Sin embargo, sí encontramos una breve pero significativa mención en el editorial del primer número de Espadaña, de la autoría de Victoriano Crémer, donde señala: "Conocíamos la existencia de núcleos de jóvenes poetas con auténtica personalidad, a quienes la magnífica plenitud de Fernando Pessoa arrebataba y sostenía."21

Esta situación de relativa abertura (que posibilita la presencia pessoana en 1944 tanto en Garcilaso como en Espadaña) contrasta, añadiendo un dato más al panorama polimorfo que intentamos definir, con la cerrazón de otras publicaciones más radicalizadas. Es el caso de El Español, subtitulado Semanario de la política y del espíritu (dependiente de la Delegación Nacional de Prensa y Propaganda, contó con una primera etapa muy activa entre 1942 y 1947, animada por Juan Aparicio), que defendía de forma programática la capacidad de los autores patrios frente a la oleada de literatura extranjera traída, sin duda, por los escritores en la línea de la vanguardia literaria anterior a la Guerra Civil. Desde sus páginas, así como desde las de otras publicaciones oficialistas (es el caso de Juventud. Semanario de combate del SEU), no fueron pocas las voces que se alzaron contra la sutileza intelectual que creían atisbar en la poesía del Veintisiete, eslabón definitivo de la cadena de la modernidad quebrada o dispersada por la guerra. José-Carlos Mainer lo ha explicado con claridad meridiana, tomando como referente la revista Garcilaso y poniendo en primera fila el nuevo paradigma estético reinante: "El resultado de aquellos condicionantes será una poesía en la que la densidad retórica y sentimental sustituirá el leve cinismo y la brillantez metafórica de la generación de 1925."22

No deja de resultar curioso pensar que este activo debate que se vive en las revistas mencionadas, y en el que habita como telón de fondo la construcción de un nuevo paradigma estético fundamentado en esa "densidad retórica y sentimental" aludida por Mainer, tenga como epicentro los mismos años en que Pessoa se hace presente en España a través de Rafael Morales, Joaquín de Entrambasaguas e Ildefonso-Manuel Gil (además de otras aportaciones menores de José García Nieto, E. Segura Covarsí, Pablo Cabañas o Gabriel Celaya, citadas por Ruiz Casanova). ${ }^{23}$ Especialmente los años centrales de esa década, tomando como balizas la traducción de "Cualquier música" en 1944 y la breve antología de Entrambasaguas de 1946 (primera de Pessoa, como es bien sabido, en España, aunque con los textos en su 
lengua original), se constituyen en el eje sobre el que se vertebra en el tiempo una amplia serie de actuaciones de aproximación entre Portugal y España, fraguada en el seno de la cultura promulgada por las dos dictaduras, que no debe pasarnos en absoluto desapercibida.

\section{Las culturas oficiales y el eje Eugénio Montes - António Ferro}

Los nuevos vínculos surgidos entre los gobiernos de España y Portugal tras la Guerra Civil, y las diferentes manifestaciones de las políticas de carácter oficialista dictadas por los respectivos ideólogos de los dos Estados, marcan sin duda un nuevo rumbo en las relaciones culturales y literarias, en cuyo seno asistimos a algunos hitos de la recepción de Fernando Pessoa. Porque, de hecho, si analizamos el contexto sociopolítico en el que surgen estas presencias del escritor luso, encontramos-exceptuando el caso, algo posterior en el tiempo, de Ildefonso-Manuel Gil-indicios más que suficientes para tejer una sólida red de personajes (secundarios a la luz del canon de la historia de la literatura española, pero de primera línea en la construcción del imaginario mítico del nacionalcatolicismo español) que cumplieron un papel fundamental en favor de esta recepción en los años centrales de la década de los 40. La aproximación entre estas dos culturas peninsulares fue muy importante en aquel momento, y siempre arbitrada por una elaborada red humana en clara comunión ideológica. En esa tela de araña delineada en los despachos y plagada de recepciones oficiales aflora una línea evidente, compartida por los mandatarios de los dos países, de acercamiento interesado a través de una concepción de la cultura dirigida y dirigista, que toma como precedente directo-y todavía vivo en los años 40-el ideal de cierta Hispanidad mítica ${ }^{24}$ (en contraposición al iberismo federalista de los republicanos españoles, considerado un peligro por los salazaristas), que hermanó el integralismo lusitano de António Sardinha y la Acción Española dirigida por Ramiro de Maeztu y el Marqués de Quintanar, auténtica base intelectual y grupal del poder franquista.

De hecho, la década de los años treinta finaliza en la península, desde este punto de vista, con dos hechos fundamentales a la luz de nuestro análisis: la publicación, en 1938, de la tercera edición del libro Defensa de la Hispanidad (la primera es de 1934), de Ramiro de Maeztu, que alcanza un relieve notable tras la muerte de su autor en 1936 a manos de los republicanos; y la firma, el día 17 de marzo de 1939, del "Tratado de amistad y no agresión” que rubrican Oliveira Salazar y el embajador de España en Portugal, Nicolás Franco, hermano del dictador. El libro de Maeztu, fundamental para comprender las raíces del movimiento de aproximación cultural que emerge en los dos países, ofrece un mapa de “Tierras y pueblos de la Hispanidad bajo Felipe II," y en él establece su autor, tras preguntarse por la presencia de Portugal y Brasil en este proyecto, su propio concepto de Hispanidad, cuya unidad ansía: "Hispánicos son, pues, todos los pueblos que deben civilización o el ser a los pueblos hispanos de la península. Hispanidad es el concepto que a todos los abarca." 25

Sin duda, los falangistas de los años 40 encuentran en este ideario uno de sus antecedentes ideológicos fundamentales, al que habría que añadir el papel que cobran en este contexto aspectos como la relectura interesada de los autores del 98, cierto Ortega y Gasset, el perfil del prestigioso Eugenio d'Ors-en su deriva del catalanismo incipiente a la Falange-y, como predecesor inmediato, Ernesto Giménez Caballero, que tuvo el carnet número cinco de Falange Española y, según su propio testimonio, rechazó el número uno con el que Primo de Rivera quiso agasajarle. ${ }^{26} \mathrm{El}$ que fuera director de La Gaceta Literaria se jactó-lo hace en una nota de 1938 incluida en la reedición correspondiente de Genio de España, cuya 
primera data de 1932, haciendo gala de su particular egocentrismo, de que en su revista (que protagoniza una sonada ruptura, tras un interesante acercamiento inicial, con respecto a la coimbrana Presença, exactamente por el imperialismo castellanista de su director) "surgieron las dos juventudes espirituales que cuajarían el porvenir de España. Los Comunistas y los Fascistas." ${ }^{27}$

A todos estos antecedentes fundamentales debemos añadir, para obtener una definición rigurosa de la realidad, dos acontecimientos: el primero de ellos es el Doctorado Honoris Causa atribuido en 1938 a Eugenio d'Ors por la Universidad de Coimbra, con todo el boato propio de la ocasión, institución a la que volverá el catalán en 1944 para rendir homenaje al ya convertido en poeta oficial Eugénio de Castro, en un encuentro que simboliza (en el mismo año en que se publica el poema de Pessoa "Cualquier música" en España y en la misma universidad que frecuentara su traductor, Rafael Morales) algo así como el momento cumbre de "un calculado proceso de institucionalización cultural común." 28 El segundo acontecimiento, de carácter más general, pero que define de forma evidente el ambiente de diálogo en que nos encontramos, es la reunión que llevan a cabo, en Sevilla y en febrero de 1942, Franco, Serrano Suñer y Salazar, en la que se definen las líneas esenciales del Pacto Ibérico y se siembran las bases del Bloque Ibérico que se anunciaría en diciembre de ese mismo año, ${ }^{29}$ sobre el cual escribirá un año después A. A. Mendes Corrêa el libro O bloco peninsular. ${ }^{30}$

De hecho, retomando el hilo de Ors, es posible trazar simbólicamente el marco esencial del tiempo que nos ocupa entre dos doctorados Honoris Causa por la Universidad de Coimbra: el ya mencionado a Xenius, en 1938, y el que recibe el mismísimo Francisco Franco el 25 de octubre de 1949, motivo fundamental del libro de Giménez Caballero Amor a Portugal, ${ }^{31}$ de ese mismo año. Los elocuentes discursos del homenaje al caudillo, inexcusables a la hora de recordar esa "densidad retórica y sentimental" a la que aludía Mainer, se recogieron de inmediato en el volumen Franco en Portugal. Actos y discursos, ${ }^{32}$ que se vio acompañado, en noviembre de ese mismo año, por el amplio reportaje gráfico del evento ofrecido en Madrid por Mundo Hispánico, ${ }^{33}$ donde se recogen también textos alusivos al acto académico y la visita de Franco a Portugal, firmados, entre otros, por Wenceslao Fernández Flórez, Eugenio Montes o Giménez Caballero.

Es importante poner de relieve que todos los nombres mencionados hasta el momento como parte fundamental del entramado de la cultura oficialista del régimen de Franco están vinculados con Portugal y gravitan alrededor de las primeras apariciones de Pessoa en España, a pesar de nunca referirse a él en sus textos. Son, de alguna manera, los hacedores del telón de fondo cultural que propicia estas apariciones, los ideólogos activos del caldo de cultivo de la aproximación luso-española que provocará la llegada del poeta portugués al lector español de los años 40.

Entre ellos, el caso del lusitanista Eugenio d'Ors es bien conocido, ${ }^{34}$ así como su temprana sintonía con el integralismo portugués-al que dedica tres glosas en el Nuevo glosario-y su admiración por Oliveira Salazar ${ }^{35}$ (prologará, como hiciera Paul Valery en su país, la edición española del libro de António Ferro Oliveira Salazar. El hombre y su obra, de 1935, que marca la presencia propagandística del salazarismo en España antes de la Guerra Civil). Wenceslao Fernández Flórez, por su parte, traduce a Eça de Queirós y prologa el libro de Luís Teixeira Perfil de Salazar, editado en Madrid en 1940, y el papel de Eugenio Montes es aún más significativo y especialmente relevante en el contexto que nos ocupa, pues es casi omnipresente en toda la red de contactos culturales establecidos alrededor de 
la política de carácter oficial, como señala Giménez Caballero en Amor a Portugal. ${ }^{36}$ Con una evolución personal que le lleva de la vanguardia ultraísta al clasicismo de posguerra y del uso del gallego al castellano, se movió ideológicamente entre Acción Española y la Falange, adquiriendo un importante protagonismo en la política cultural franquista, en cuyo contexto asume la dirección del Instituto Español de Lisboa entre 1943 y 1950, cargo que compatibiliza con el de Agregado Cultural de la embajada española.

Desde su atalaya lisboeta-desde donde colabora asiduamente con el periódico falangista Arriba-con un pie en la cultura y otro en la vida política, Eugenio Montes se convierte en un activo importantísimo en el estrechamiento de relaciones entre los dos países, desempeñando un papel notable tanto de anfitrión lisboeta de los representantes de la vida cultural española, como de contacto fiel y cercano con el escritor António Ferro, el amigo de Pessoa transformado en hombre de confianza de Salazar-será director del Secretariado de Propaganda Nacional-y en el eje sobre el que gravitan los principales acontecimientos de esta aproximación.

De hecho, Montes albergaba la esperanza de esa comunión hispánica desde mucho tiempo antes, al menos desde 1935, cuando llega a Madrid desde Berlín, donde era corresponsal de $A B C$. En la capital madrileña visita la redacción de Acción Española, donde encuentra a los prohombres de la causa, como el propio Maeztu, Giménez Caballero, Pedro Sáinz Rodríguez, José María Pemán—a quien Eugenio d'Ors llamaba “el Gran Capitán”—— el Marqués de Quintanar, en cuya compañía creyó Montes encontrar personas con suficiente prestigio intelectual como para combatir a los republicanos liberales, vislumbrando para ello la formación de un grupo constituido por escritores, pensadores, poetas y catedráticos.

Así, en 1944, mientras Rafael Morales traduce el poema de Pessoa, Montes-identificado en la cubierta, a más honra oficial, como miembro de la Real Academia Española-publica Interpretación de Portugal, ${ }^{38}$ después recogido en su volumen Elegías europeas (1949), ${ }^{39}$ en cuyas páginas sitúa al gobierno de Salazar con la misma dimensión histórica que los del Marqués de Pombal o la dinastía de Avis. ${ }^{40}$ Dos décadas después, en el "Prólogo" que escribe para el libro Diálogo peninsular ${ }^{41}$ del Marqués de Quintanar, señalará aún la actualidad del rumbo marcado por Acción Española y por el libro La alianza peninsular ${ }^{42}$ de António Sardinha.

El contacto del bien relacionado Director del Instituto Español con António Ferro se revela fundamental para la creación del sistema literario de relaciones que estamos describiendo, pues el autor de Leviana y Teoria da Indiferença amparó y ayudó a divulgar en Portugal trabajos de numerosos escritores españoles. No en vano, en 1930 ya se había referido a esta faceta suya el Conde de Santibáñez del Río, cuando define al escritor, destacando su trabajo periodístico, como un "literato que ha traspasado las fronteras y por cuya pluma viven en las columnas del Diário de Notícias todas las ideologías y todas las figuras políticas de Europa y América." ${ }^{33}$ El Secretariado de Propaganda Nacional de Ferro, como es evidente, estaba en sintonía y perfectamente coordinado con el Servicio Nacional de Propaganda dirigido por Dionisio Ridruejo (sustituido en el cargo por Juan Aparicio en 1942), con lo cual la acción cultural conjunta era el resultado natural de la profunda conexión ideológica existente.

Los años centrales de la década son, en esta sintonía, especialmente favorables al diálogo cultural entre los dos países, gracias a las relaciones establecidas entre Ferro-auténtico ideólogo y constructor de la imagen de Salazar en el extranjero- ${ }^{44}$ y la poderosa plataforma cultural asociada al poder oficial creada por el régimen franquista. Son estos años que siguen a 1945 los que señala José-Carlos Mainer, exactamente, como el momento en el que 
se inicia una "nueva conciencia poética en España," ${ }^{5}$ en la que cobran una importancia fundamental los viajes realizados por varios de los más notables escritores vinculados a la oficialidad a América, circunstancia ésta a la que cabría añadir la labor desarrollada por otros dos grandes viajeros, Montes y Ferro, en primera línea del descubrimiento ibérico.

Resulta sumamente iluminador, en este contexto, citar algunos de los acontecimientos que envuelven esta acción conjunta y que, sin duda, sentaron las bases culturales para el desembarco pessoano en España, pues ponen, una vez más, de manifiesto las profundas relaciones existentes entre los aparatos oficialistas de ambos países. El punto de inicio tal vez más relevante de esta entente se produce exactamente el 4 de febrero de 1944, apenas tres meses antes de la publicación del poema "Cualquier música" en la revista Garcilaso. Otra de las cabeceras más importantes del momento, Escorial, que había dirigido Ridruejo y después otro hombre interesado por Portugal, José María Alfaro (uno de los poetas fundadores de Falange Española, quien cifra su conocimiento y admiración por Pessoa en la mediación amistosa de Almada Negreiros, allá por los años treinta, según llega a afirmar en un artículo titulado "La poesía de Pessoa," que ve la luz en el diario ABC el 19 de agosto de 1979), organiza ese día una conferencia madrileña de António Ferro, celebrada con alborozo por la prensa, que tiene como título "Oliveira Salazar, íntimo" y como presentador del acto, una vez más, a Eugenio Montes.

Es el arranque, como anticipábamos, de un intenso programa de intercambio realizado de forma especial entre 1944 y 1946, y que tiene como eventos fundamentales los siguientes: el 10 de marzo de 1944, encontramos a Ernesto Halffter en Lisboa, divulgando la música española; a finales de ese mismo mes, el poeta sevillano Joaquín Romero Murube realiza una conferencia en la misma ciudad; el 11 de abril, es la Orquesta Nacional de España la que actúa en el teatro São Carlos, mientras que en ese mismo mes António Ferro organiza una exposición de arte popular portugués en el contexto de la Feria de abril de Sevilla. Un mes después, siguiendo con este intenso calendario, encontramos a José María Alfaro pronunciando una conferencia titulada "El panorama actual de la literatura española" en Lisboa, en un acto presentado por Eugenio Montes y presidido por Nicolás Franco, y el 12 de julio se estrena el Frei Luis de Sousa de Garrett en el teatro Calderón de Madrid. En esas mismas semanas comienza en $A B C$ una breve pero intensa serie de artículos, titulada "Telegrama a António Ferro," firmada por Tomás Borrás (el autor de Noche de Alfama, de 1926, que había frecuentado la Lisboa literaria modernista junto a su mujer, la célebre tonadillera La Goya, y que fue también militante de Falange Española), solicitando que se implicara en la creación de una Residencia de Portugal en la Ciudad Universitaria madrileña.

Siguiendo con este itinerario, unos meses más tarde, en febrero de 1945, tenemos a António Ferro nombrado académico correspondiente de la Real Academia de la Historia española, y en abril de ese mismo año es la Orquesta Sinfónica Nacional de Portugal la que retribuye visita actuando en Madrid. En junio, la Feria del Libro de la capital española ofrece la presencia de varias casetas dedicadas exclusivamente a la literatura portuguesa, y el día 8 de ese mes la revista Escorial organiza de nuevo una conferencia en la capital, en este caso a cargo de Pedro de Moura e Sá (crítico literario vinculado a la Emisora Nacional portuguesa y autor del volumen Espanha viva, donde recogió artículos publicados en el Diário Popular), titulada "Presencia de la literatura portuguesa."

Ya en 1946, año en que el Secretariado Nacional de Informação portugués publica, sintomáticamente en español, el libro Visión de la literatura portuguesa ${ }^{46}$ de José Osório de Oliveira (que contiene información y un retrato de Fernando Pessoa y se transforma en 
precedente inmediato de la Antologia da lírica portuguesa contemporânea, ${ }^{47}$ publicada un año después por António Jorge Dias en la Universidad de Santiago de Compostela, que incluye el poema pessoano "Mar portugués"), Eugenio Montes habla en Lisboa sobre "Eça de Queirós o el estilo," y en junio de ese mismo año encontramos la presencia de un pabellón portugués en la Feria del Libro de Barcelona.

Es en medio de este intenso clima de acercamiento cultural entre los dos países donde germina la segunda recepción de Pessoa en España. El 26 de octubre de ese mismo año de 1946, Eugenio Montes hace de maestro de ceremonias y autor del discurso introductorio del recital poético que llevan a cabo Adriano del Valle, Gerardo Diego y José García Nieto en el Museu das Janelas Verdes, al amparo de la Exposición del Libro Español organizada en Lisboa por Adriano, a las órdenes de Dionisio Ridruejo, que fuera fundador del periódico La Falange, jefe nacional de Propaganda y miembro de la Junta Política de Falange. ${ }^{48}$ En esa sesión, que pone palmariamente de manifiesto la línea oficial de la lírica española presentada en Portugal, se leyeron también poemas de Manuel Machado y del propio Ridruejo, alternados con intervenciones musicales del pianista Antonio Lucas Moreno.

Hay, curiosamente, tres circunstancias que relacionan a los tres poetas protagonistas del recital del Museu de Arte Antiga con la huella de Pessoa en España. La primera tiene que ver con las entrevistas que concede en los años 40 un triunfal Adriano del Valle (otro ultraísta en el seno de Falange, de la mano de su amigo Eugenio d'Ors, con un papel importante en la política cultural y el único escritor español que mantuvo entre 1923 y 1924 una relación de amistad con Pessoa) a diversos medios lisboetas en sus viajes a la capital portuguesa, rememorando, con un punto de mixtificación, su relación con el autor de Mensagem. ${ }^{49}$

La segunda, desconocida hasta el momento, tiene como protagonista a Gerardo Diego, autor, como es sabido, de una traducción del poema pessoano "O mostrengo" ("El monstruo"), que publica en Tántalo. Versiones poéticas. ${ }^{50}$ Pues bien, esa misma traducción fue leída en España en dos recitales poéticos promovidos por António Ferro que coinciden exactamente con los años en que aparecen los dos hitos de la recepción pessoana que tienen como protagonistas a Morales y Entrambasaguas: 1944 y 1946. En concreto, el día 26 de abril de 1944 se realiza en el Alcázar de Sevilla un recital de poesía portuguesa en el que la actriz Amelia Rey Colaço lee poemas de Antero, Eugénio de Castro, Nobre, Pessoa o Régio, traducidos, según señala el diario $A B C$ en su edición sevillana del día siguiente, ${ }^{51}$ por Dámaso Alonso, Gerardo Diego y José María de Cossío. Los tres, cada uno a su manera, se habían acercado a la literatura portuguesa: Dámaso, que publica en 1944 Hijos de la ira y Oscura noticia, había traducido y estudiado a Gil Vicente; Cossío había hecho lo propio con Fidelino de Figueiredo y había publicado dos importantes colecciones de sonetos portugueses; y Diego-que participará años después en un homenaje a Camões-por su parte, había traducido el poema citado de Pessoa. En el segundo de los recitales mencionados, celebrado en el hotel Ritz de Madrid el 25 de junio de 1946, volvieron a declamarse, esta vez a cargo de Maria Manuela Couto Viana, traducciones realizadas por los tres mismos escritores españoles, de acuerdo con la crónica del evento publicada en el diario $A B C$ del día $26,{ }^{52}$ en la que se afirma que el poema de Fernando Pessoa traducido por el autor de Imagen fue, efectivamente, "El monstruo."

La tercera circunstancia que merece nuestra atención se sitúa cronológicamente entre las dos lecturas del poema traducido por Diego, y tiene como protagonista al tercer participante en la lectura poética celebrada en el Museu das Janelas Verdes: José García Nieto. Éste publica en el diario Línea de Murcia el 28 de febrero de 1945 un artículo sobre Pessoa 
escrito con motivo de la reciente edición en Portugal de las Poesias de Álvaro de Campos (1944) aparecidas en la editorial Ática, lo cual nos habla de la prontitud con que los poetas españoles vinculados a esta línea oficialista acompañaban las novedades editoriales portuguesas, en un proceso en el que no es difícil imaginar el trabajo de mediación desarrollado por Eugenio Montes.

En este texto, que ha pasado casi desapercibido, y haciéndolo tras el seudónimo de José María Lizar, el que fuera fundador y director de Garcilaso dedica a Pessoa estas significativas palabras, que se constituyen en unas de las primeras opiniones críticas de peso vertidas en España sobre Pessoa:

Dentro de las letras portuguesas es Fernando de Pessoa, sin duda alguna, el más grande poeta contemporáneo. En Pessoa sí que la línea de la poesía lírica del país hermano, se trunca y se vitaliza, toma rumbo distinto y eterno a la vez, ordena ya para mucho tiempo las voces que han de sucederle, marca un punto de fuego en el atormentado tiempo del decir de los hombres. Hablar de Pessoa en Portugal es sentir alrededor nuestro la unanimidad de todas las preferencias, es ver coincidir, como de milagro, a tirios y troyanos para alabar al poeta genial, ya desaparecido, pero para siempre paladín de la poesía lusitana durante una época ancha y profunda..$^{53}$

García Nieto cita el único libro publicado en vida por Pessoa, Mensagem (que aparecería ese mismo año de 1945 en la editorial Ática, tras su primera edición en 1934) y elige como los poemas más significativos de Álvaro de Campos la "Ode Marítima” y “Tabacaria." Teniendo en cuenta el fragmento citado, además, no parece demasiado arriesgado pensar que la opinión del poeta garcilasista calase en el catedrático de la Universidad de Madrid Joaquín de Entrambasaguas, pues la forma en que comienza la nota preliminar de su breve antología pessoana de 1946 es igual de firme y asertiva que la de García Nieto, y sirve también para situar a Pessoa como el poeta de referencia de la literatura portuguesa del momento, desbancando de ese lugar de privilegio en España a Teixeira de Pascoaes:

Es indudable que de toda la lírica lusitana contemporánea-pese a los destacados poetas con que cuenta-la figura más importante y trascendental es la de Fernando Pessoa. (...) En España, por desidia imperdonable, no se conoce la obra de Fernando Pessoa, que abre nuevos horizontes a la poesía lírica de nuestro tiempo, pero en Portugal la crítica, unánimemente, reconoce en él uno de esos poetas cuyo nombre marca una época literaria. ${ }^{54}$

El prestigioso CSIC, centro editor de estas Poesías de Pessoa, nace vinculado al nacionalcatolicismo del régimen, y es en ese contexto donde Entrambasaguas dirige desde 1942 tanto la revista de la que la antología pessoana forma parte como suplemento, Cuadernos de literatura contemporánea, como aquella otra en la que se metamorfosea en 1947, con el título de Cuadernos de literatura. En el número 3 de esta nueva cabecera, que también presta alguna atención a la literatura portuguesa moderna, editado en mayo-junio de 1947, aparece una reseña de las Páginas de doutrina estética pessoanas preparadas por Jorge de Sena para la editorial Inquérito, firmada por E. Segura Covarsí ("Un libro en prosa de Fernando Pessoa"). En ese mismo ejemplar encontramos también, con motivo de una nota sobre la revista coimbrana Mensagem, una referencia al libro homónimo y otra a dos poemas concretos de ese volumen: "Nevoeiro" y "Terceiro aviso," mientras que en el tomo sexto de Cuadernos de Literatura (1948) encontramos el artículo de Pablo Cabañas "La poesía de Fernando Pessoa y otros ensayos." Sin duda, la fascinación de Entrambasaguas por Pessoa se deja notar en las páginas de estas revistas, fundadas para contribuir al propósito 
de crear un ecosistema riguroso y de matriz oficial en los estudios literarios españoles que siguen a la Guerra Civil.

El autor de la antología pessoana se convierte, así, en uno de los mediadores más importantes para la llegada de la literatura portuguesa a España en este contexto oficialista. No tradujo a autores portugueses, pero fue uno de los principales estudiosos e introductores de la literatura lusa en el espacio de la universidad española de los años 40 y 50, dejando en diferentes revistas especializadas notas o reseñas sobre Camões, Eça de Queirós, Fernando Namora, Jorge de Sena, António Gedeão, Carlos Lobo de Oliveira o Joaquim Paço d'Arcos. ${ }^{55}$ Entrambasaguas dedica una atención especial a Pessoa, plasmada tanto en la antología de 1946 (para cuya preparación se sirve, fundamentalmente, de la consulta de Poesia de Fernando Pessoa, de Adolfo Casais Monteiro, cuya segunda edición aparece un año antes) como en el libro que le dedicará en 1955: Fernando Pessoa y su creación poética. ${ }^{56}$ En este volumen, pionero en los estudios monográficos dedicados en exclusividad al creador de los heterónimos fuera de Portugal, refunde y amplía notablemente la nota preliminar de la muestra de 1946 e incluye también dos extensas conferencias ofrecidas, en 1952, en las universidades de Lisboa y Coimbra, textos estos publicados también en los números 5 y 6 de la Revista de Literatura, ambos en 1954. Sin duda, Entrambasaguas fue un lector extraordinariamente informado sobre la literatura portuguesa de su tiempo, como lo demuestran los cuatro centenares de títulos en portugués que se conservan, aún hoy, en el fondo de su biblioteca personal, mantenido por la Universidad de Castilla La Mancha, y entre los cuales destacan varios títulos de Pessoa. ${ }^{57}$

\section{Conclusión}

Todas estas circunstancias nos sirven para configurar la verdadera magnitud de este intercambio entre los sistemas oficialistas de la cultura en los dos países, que constituye el entramado en el que brotan muchas de las primeras apariciones de Pessoa en España en los años 40. Podemos pensar, incluso, que el artículo de García Nieto y la breve antología de Entrambasaguas presentan, sin hacerlo explícito, la poesía pessoana como una posible respuesta ante el exceso academicista y neoclásico de las propuestas estéticas dominantes en España, amparándose en una lectura biografista y tomando como clara base de interpretación a Adolfo Casais Monteiro y los presencistas. Así, se va construyendo una imagen de Fernando Pessoa en la que prevalece, siempre con el telón de fondo del deslumbramiento de los heterónimos, el criterio de la importancia de la imaginación y un proceso intelectual colmado "de artificio" ${ }^{8}$ por encima de los avatares del tiempo y el espacio.

En este contexto, sin embargo, llama poderosamente la atención el hecho de que el Pessoa de Mensagem, que podría ser desde su impulso nacionalista el más cercano a las preferencias y gustos estéticos e ideológicos de sus mediadores españoles, no solo no sea el centro de su campo de interés, sino que sea prácticamente inexistente hasta el ensayo de Entrambasaguas de 1955. Aunque Ática había publicado el libro diez años antes dentro de las Obras Completas, exactamente en el meridiano de todos los contactos relatados y en el momento de máxima atención de los escritores e ideólogos culturales hacia Portugal, Mensagem es un vacío importante en estos años de recepción, sepultado bajo la fascinación que los heterónimos provocan entre los primeros lectores españoles. Este hecho deberá ser también interpretado, bien como un signo del desigual conocimiento que tuvieron de la obra pessoana, o bien como una opción manifiesta realizada por sus primeros mediadores, 
que ven en la poesía de los heterónimos (y en especial en la de Álvaro de Campos, el más divulgado) una propuesta diferente y atractiva ante la encrucijada en que se encontraba la poesía española. Sea como fuere, la presencia de Pessoa en España en los años 40 responde a un contexto cultural muy determinado-que, de alguna forma, anticipa el "final del fascismo dentro de la duración franquista" 59 - sometido por criterios y fundamentos de carácter ideológico que crearon la base para la posterior recepción del poeta ya en los años 50, cuando el ensayo de Entrambasaguas lo legitima en el ambiente universitario y las nuevas traducciones realizadas a finales de la década por el lusista Ángel Crespo (sus Poemas de Alberto Caeiro $^{60}$ son de 1957) comienzan a sentar los pilares de la recepción y asentamiento definitivo del escritor en el contexto del sistema literario español.

\section{Notas}

1. Antonio Sáez Delgado, "Inscriptions. Rogelio Buendía, primer traductor de Fernando Pessoa en España," Insula 635 (1999): 3-4.

2. Véanse los catálogos de dichas exposiciones: Antonio Sáez Delgado y Jerónimo Pizarro (coord.), Fernando Pessoa em Espanha (Lisboa: Babel/Biblioteca Nacional de Portugal, 2014) y Fernando Pessoa en España (Madrid: Biblioteca Nacional de España, 2014).

3. Nicolás Extremera Tapias \& Luisa Trías Folch, "Fernando Pessoa en España," Cuadernos Hispanoamericanos 407 (1984): 151-55; Nicolás Extremera Tapias \& Luisa Trías Folch, "Pessoa, en España(II)," Cuadernos Hispanoamericanos 425 (1985): 165-170.

4. César Antonio Molina, "Pessoa y España," Anthropos 74-75 (1987): 47-59.

5. Pilar Vázquez Cuesta, "Pessoa y la generación del 27," República de las letras 21 (1988): 105116.

6. Ángel Crespo, Con Fernando Pessoa (Madrid: Huerga \& Fierro, 2000), 453-89.

7. José Francisco Ruiz Casanova, "Las atípicas recepción e influencia de Fernando Pessoa en España" in Dos cuestiones de literatura comparada: traducción y poesía. Exilio y traducción (Madrid: Cátedra, 2011), 178-94.

8. Antonio Sáez Delgado, "Fernando Pessoa em Espanha: Uma visão panorámica" in Fernando Pessoa em Espanha (Lisboa: Babel/Biblioteca Nacional de Portugal, 2014) 13-24; Antonio Sáez Delgado, Pessoa y España (Valencia: Pre-Textos, 2015).

9. Eduardo Alonso Romo, "Letras en tiempos de dictaduras," in RELIPES: Relações linguísticas e literárias entre Portugal e Espanha desde o início do século XIX até à actualidade, ed. Gabriel Magalhães (Salamanca: Celya/UBI), 171-202.

10. Fernando Pessoa, Poesías. Suplemento Sexto de Cuadernos de literatura contemporánea, selección e introducción de Joaquín de Entrambasaguas (Madrid: Consejo Superior de Investigaciones Científicas, 1946).

11. Ildefonso-Manuel Gil, "La poesía de Fernando Pessoa," Ensayos sobre poesía portuguesa (Zaragoza: Heraldo de Aragón, 1948), 7-40.

12. Jordi Cerdà, "Apuntes para la recepción de Pessoa en España (1944-1960)," Cuadernos Hispanoamericanos 660 (2005): 53-66.

13. Jordi Gracia, La resistencia silenciosa (Barcelona: Anagrama, 2004), 51.

14. Antonio Sáez Delgado y Filipa María Valido-Viegas de Paula-Soares, Almada Negreiros en Madrid (Madrid: Universidad Autónoma de Madrid, 2017).

15. El poema había aparecido originariamente en Presença no 10, en marzo de 1928, y formó parte de Poesias, colectánea publicada en Lisboa por la editorial Ática en 1942, como volumen inicial de unas primeras Obras completas de su autor.

16. Charles David Ley, La Costanilla de los diablos (memorias literarias 1943-1952), (Madrid: José Esteban Editor, 1981).

17. Rafael Morales, "Laranjeira y Unamuno" Escorial 17 (1945): 438-447 y "La joven poesía portuguesa," La estafeta literaria 15 (1944): 9. Sobre Rafael Morales y Victoriano Crémer y sus relaciones con la literatura portuguesa del momento, véase Antonio Rivero Machina, 
"Portugal y la simetría. Victoriano Crémer y Rafael Morales ante el espejo ibérico," Suroeste 5 (2015): 167-75.

18. Jordi Gracia y Domingo Ródenas, Derrota y restitución de la modernidad 1939-2010 (Barcelona: Crítica, 2011), 97.

19. Jaume Pont, "Una revista poètica de la immediata postguerra: Entregas de poesía (Barcelona, 1944-1947). Trajectòria, programa i funció," in Literatura comparada catalana i espanyola al segle XX: gèneres, lectures i traduccions (1898-1951) (Lleida: Punctum \& Trilcat), 49-63.

20. Joaquín Juan Penalva, La revista Escorial: poesía y poética. Trascendencia literaria de una aventura cultural en la alta posguerra (tesis Doctoral, Universidad de Alicante, 2005), 196.

21. Victoriano Crémer, "Editorial”, Espadaña 1 (1944): 10.

22. José Carlos Mainer, Falange y literatura (Barcelona: Labor, 1971), 49.

23. Ruiz Casanova, "Las atípicas recepción," 182.

24. El Conde de Santibáñez del Río defiende fervientemente, desde un trasfondo ideológico, el Hispanismo como sustituto del Iberismo en su libro Portugal y el Hispanismo (Madrid: Sindicato de Publicidad, 1920), 47.

25. Ramiro de Maeztu, Defensa de la Hispanidad, $3^{\text {a }}$ ed. (Valladolid: Aldus), 34.

26. Mónica Carbajosa y Pablo Carbajosa, La corte literaria de José Antonio (Barcelona: Crítica, 2003), 82.

27. Ernesto Giménez Caballero, Genio de España (Barcelona: Planeta, 1983), 22.

28. Antonio Rivero Machina, Más allá de la posguerra: poesía y ámbito literario (1939-1950) (tesis Doctoral, Universidad de Extremadura, 2016), 698.

29. Juan Carlos Jiménez Redondo, Franco e Salazar. As relações luso-espanholas durante a guerra fria (Lisboa: Assírio \& Alvim, 1996), 53-4.

30. A. A. Mendes Corrêa, O bloco peninsular (Lisboa: Tipografia da Editorial Império, 1943).

31. Ernesto Giménez Caballero, Amor a Portugal (Madrid: Ediciones Cultura Hispánica, 1949).

32. Franco en Portugal: Actos y discursos (Madrid: Publicaciones españolas, 1949).

33. Mundo Hispánico, suplemento especial (Madrid: noviembre de 1949).

34. Jordi Cerdà, "Eugenio d'Ors y Portugal," Congreso internacional de historia y cultura en la frontera (Cáceres: Universidad de Extremadura, 2000), 525-41.

35. Pedro Sainz Rodríguez, ensayista y editor, que fuera Ministro de Educación en el primer gobierno franquista, llegó a decir de Salazar que "Era un excelente escritor portugués. Sus libros y discursos ocupan un lugar distinguido en la literatura portuguesa de su época. Tenía una gran cultura literaria y eso se nota en todos sus escritos.... Pedro Sainz Rodríguez, Testimonio y recuerdos (Barcelona: Planeta, 1978), 284.

36. Como reflejo de las relaciones establecidas por Eugenio Montes con António Ferro y el régimen de Salazar, téngase en cuenta que Ernesto Giménez Caballero, en su libro Memorias de un dictador (Barcelona: Planeta, 1979), 224, relata que presentó Amor a Portugal a un concurso de obras extranjeras convocado por las instancias oficiales portuguesas, siendo Ministro de Propaganda António Ferro, con la convicción de que lo ganaría, hecho que no ocurrió, concluyendo GC con unas palabras que son el diagnóstico exacto del clima cultural en que vivían: "llegué a sospechar que no fue Ferro, sino el propio Salazar quien me lo negó. Mientras un Eugenio Montes había escrito mucho del gran gobernante portugués, yo nada.”

37. José María Pemán, Mis almuerzos con gente importante (Barcelona: Dopesa, 1972), 68.

38. Eugenio Montes, Interpretación de Portugal, separata $n^{\circ} 16$ de la Revista de Estudios Políticos (Madrid: Instituto de Estudios Políticos, 1944).

39. Eugenio Montes, Elegías europeas (Madrid: Afrodisio Aguado, 1949).

40. Ibid., 143.

41. Marqués de Quintanar, Diálogo peninsular (Madrid: Ediciones cultura hispánica, 1964).

42. António Sardinha, La alianza peninsular (Segovia: Imprenta El Adelantado, 1939).

43. Conde de Santibáñez del Río, Por tierras de Portugal (Madrid: Compañía general de artes gráficas, 1930), 45.

44. Margarida Acciaiuoli, António Ferro, a vertigem da palabra. Retórica, política e propaganda no estado novo (Lisboa: Bizâncio, 2013), 117.

45. Mainer, Falange y literatura, 53. 
46. José Osório de Oliveira, Visión de la literatura portuguesa (Lisboa: Edições SNI, 1946).

47. António Jorge Dias, Antologia da lírica portuguesa contemporânea (Santiago de Compostela: Universidad de Santiago de Compostela, 1947).

48. Jordi Gracia, La vida rescatada de Dionisio Ridruejo (Barcelona: Anagrama, 2008), 316.

49. Sáez Delgado, Pessoa y España, 67 y ss.

50. Gerardo Diego, Tántalo. Versiones poéticas (Madrid: Ágora, 1960).

51. "La hermandad hispano-portuguesa. Una fiesta de arte ofrecida por la Misión cultural que vino a Sevilla," $A B C$, Madrid, 27 abril 1944), 20.

52. "Don Antonio Ferro en Madrid. Fiesta de hermandad hispano-portuguesa," $A B C$, Madrid, 26 julio 1946, 17.

53. José María Lizar (José García Nieto), "Letras de Portugal. Fernando Pessoa," Línea, Murcia, 2 febrero 1945,5 .

54. Joaquín de Entrambasaguas, "Nota preliminar," en Pessoa, Poesías, 3-4.

55. M. Correia Fernandes, Literatura portuguesa em Espanha. Ensaio de uma bibliografía (18901985) (Porto: Livraria Telos Editora, 1986).

56. Joaquín de Entrambasaguas, Fernando Pessoa y su creación poética (Madrid: CSIC, 1955).

57. Obras de Fernando Pessoa conservadas en la Biblioteca Entrambasaguas: A nova poesia portuguesa (Lisboa, Inquérito, 1944), Fernando Pessoa (Lisboa: Confluência, 1945), Obras Completas (ocho tomos en cuatro volúmenes, Lisboa: Ática, 1945-1963), Páginas de doutrina estética, ed. Jorge de Sena (Lisboa: Inquérito, 1946), Alguns dos "35 sonetos" de Fernando Pessoa, trad. Adolfo Casais Monteiro y Jorge de Sena (São Paulo: Clube de Poesía, 1954).

58. Ildefonso-Manuel Gil, 33.

59. Gracia, La resistencia silenciosa, 242.

60. Fernando Pessoa, Poemas de Alberto Caeiro, selección, versión, epílogo y notas de Ángel Crespo (Madrid: Rialp, 1957). 